\title{
ISDSN Sensor System Phase One Test Report
}

September 2011

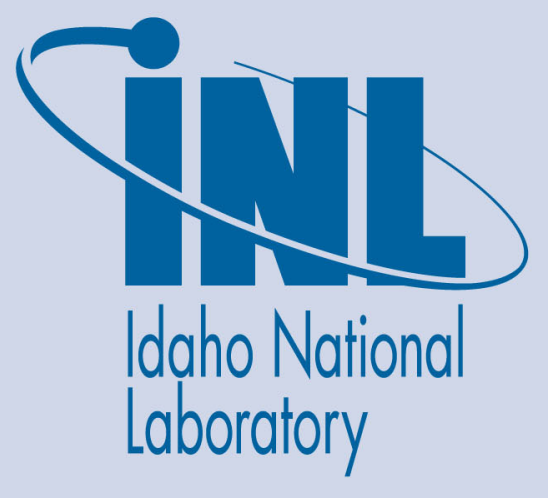

The INL is a U.S. Department of Energy National Laboratory operated by Battelle Energy Alliance 


\section{DISCLAIMER}

This information was prepared as an account of work sponsored by an agency of the U.S. Government. Neither the U.S. Government nor any agency thereof, nor any of their employees, makes any warranty, expressed or implied, or assumes any legal liability or responsibility for the accuracy, completeness, or usefulness, of any information, apparatus, product, or process disclosed, or represents that its use would not infringe privately owned rights. References herein to any specific commercial product, process, or service by trade name, trade mark, manufacturer, or otherwise, does not necessarily constitute or imply its endorsement, recommendation, or favoring by the U.S. Government or any agency thereof. The views and opinions of authors expressed herein do not necessarily state or reflect those of the U.S. Government or any agency thereof. 


\section{ISDSN Sensor System Phase One Test Report}

September 2011

Idaho National Laboratory Idaho Falls, Idaho 83415

http://www.inl.gov

Prepared for the

U.S. Department of Energy

Office of Nuclear Energy

Under DOE Idaho Operations Office

Contract DE-AC07-05ID14517 



\begin{abstract}
This Phase 1 Test Report documents the test activities and results completed for the Idaho National Laboratory (INL) sensor systems that will be deployed in the meso-scale test bed (MSTB) at Florida International University (FIU), as outlined in the ISDSN-MSTB Test Plan. This report captures the sensor system configuration tested; test parameters, testing procedure, any noted changes from the implementation plan, acquired test data sets, and processed results.
\end{abstract}




\section{CONTENTS}

ABSTRACT

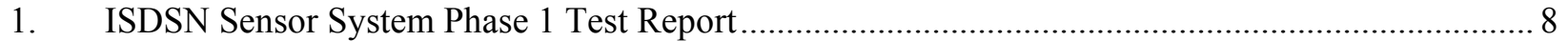

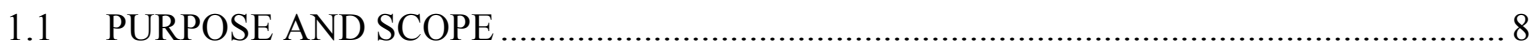

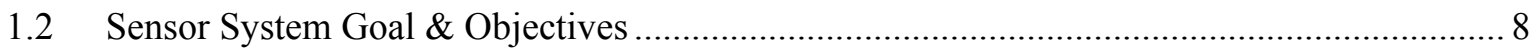

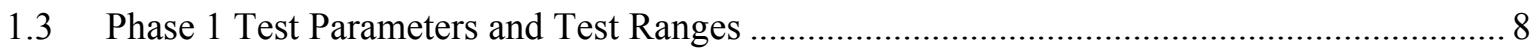

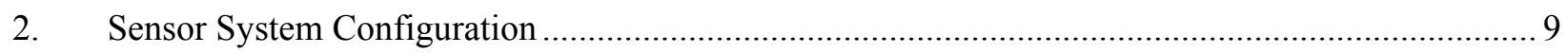

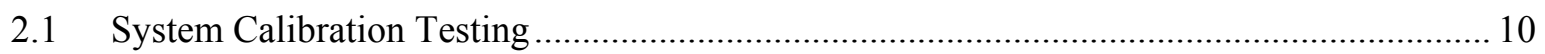

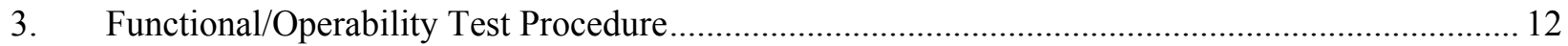

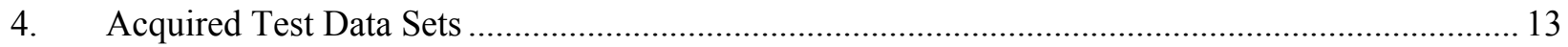

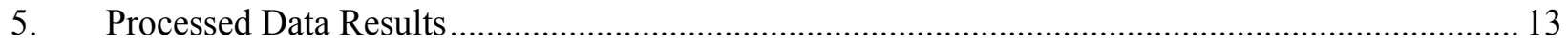

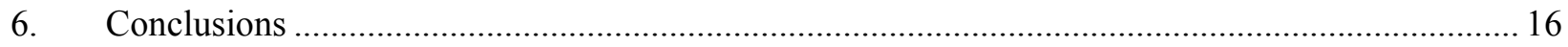

7. Attachment I. Calibration Sheet for Advanced Tensiometers ................................................... 17

8. Attachment II. Example Data Set for Thermocouple Measurements......................................... 18

9. Attachment III. Example Data File for Electrical Resistivity System ........................................... 20

\section{FIGURES}

Figure 1: Advanced Tensiometer Configuration.

Figure 2: The resistivity array with thermocouples. The total array is $8 \mathrm{ft}$ long with electrodes every 10in along the array and thermocouples distributed between every other electrode. A total of 10 electrodes and 5 thermocouples make up the array ......

Figure 3. Arrays in shipping configuration

Figure 4. Construction of an electrode-thermocouple string. Picture shows only two electrodes (tin-plated copper) on either side of a thermocouple (i. e., a fraction of the entire string) 9

Figure 5. Concrete tube adjacent to water tank. Sensors hooked to multiplexers (gray boxes) and transmitter/receiver (black box)

Figure 6. Front view of test setup. The white box is the Campbell enclosure for ADAMS controller for the thermocouples, with the control computer to left. Computer in middle of photo is for electrical resistivity system which is the two grey boxes 1 black box, power supply and laptop. 
Figure 7. QA/QC plot showing percent difference in the reciprocal of the resistivity measurement (y axis) for electrode data sets obtained from the grouted column (x-axis is the number of data sets collected).

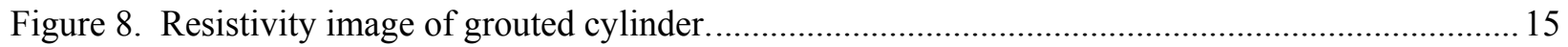

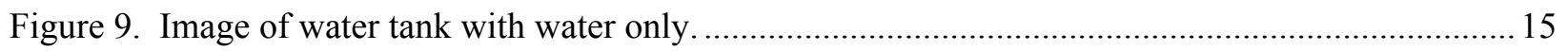

Figure 10. Image of water tank with metal object in water. ........................................................... 16

\section{TABLES}

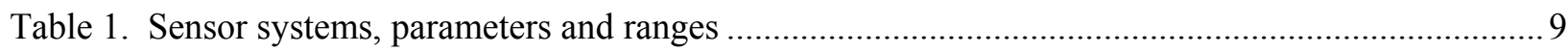

Table 2. Measurement schedule and reciprocity results (V/I) for water tank electrodes........................ 11

Table 3. Thermocouple measurements before and immersed in ice bath. ............................................ 12

Table 4. Hourly temperature readings for the cement column........................................................... 13 


\section{ISDSN Sensor System Phase 1 Test Report}

\subsection{PURPOSE AND SCOPE}

This Phase 1 Test Report documents the test activities and results completed for the Idaho National Laboratory (INL) sensor systems that will be deployed in the meso-scale test bed (MSTB) at Florida International University (FIU), as outlined in the ISDSN-MSTB Test Plan. This report captures the sensor system configuration tested; test parameters, testing procedure, any noted changes from the implementation plan, acquired test data sets, and processed results.

\subsection{Sensor System Goal \& Objectives}

INL will deploy an electrical resistivity network, thermocouples and advanced tensiometers within a grout monolith (i.e., MSTB) at FIU to determine if these sensor systems can detect fluid and monitor for fluid migration through the monolith. A deployed electrical resistivity network will monitor for resistivity changes in the monolith that could indicate the presence of fluid. Thermocouples will be placed proximal to the electrodes in the resistivity network to register a temperature change when fluid saturates the grout surrounding the sensor. Advanced tensiometers will measure the fluid potential adjacent to the fluid injection tubes to assess the development and advancement of the fluid front in the monolith. The AT sensor dimensions are 24 in by $3 / 4$ in, the PVC tube is 1 in schedule 80 that will run from the surface to depth. A comparison of measurements between different sensor systems will demonstrate with high confidence the ability or inability of these systems to detect and monitor fluid flow in a grout monolith.

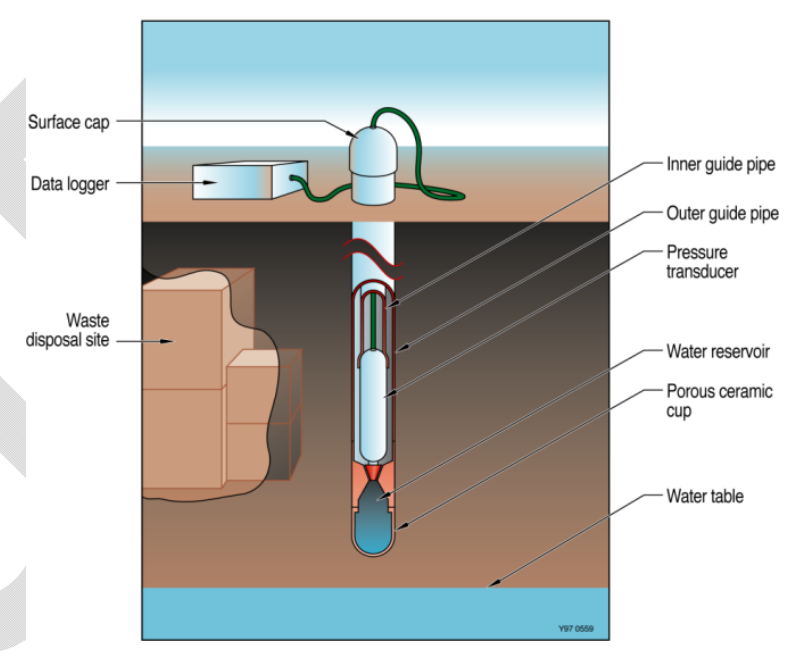

Figure 1: Advanced Tensiometer Configuration

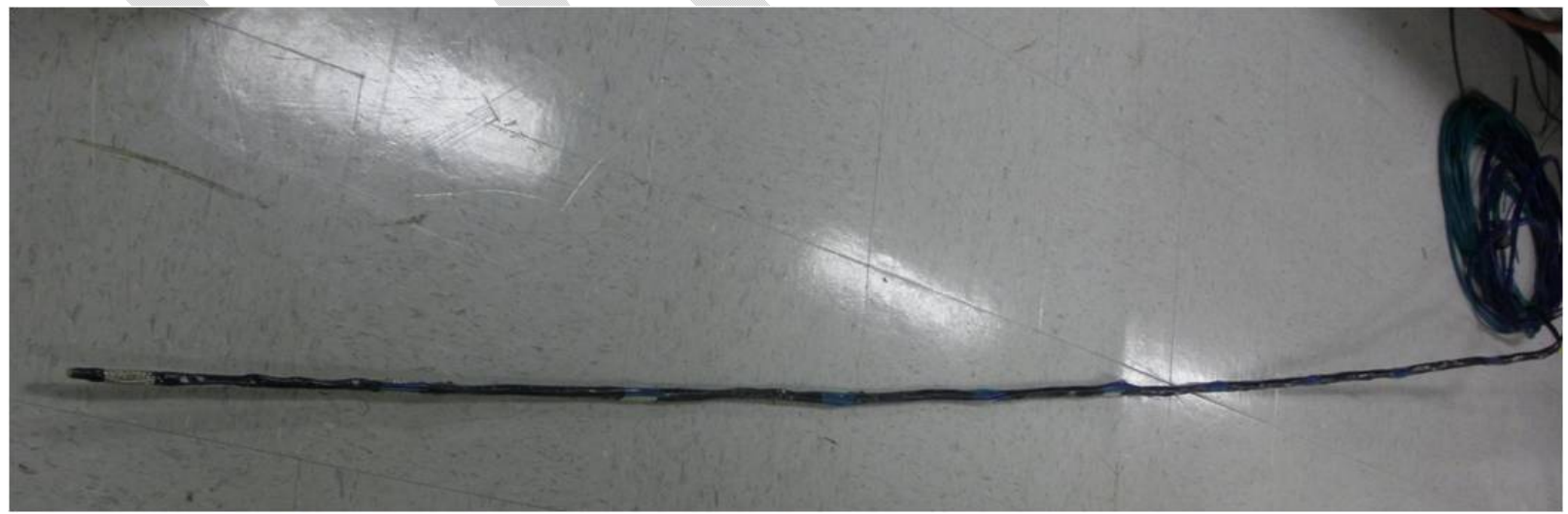

Figure 2: The resistivity array with thermocouples. The total array is $8 \mathrm{ft}$ long with electrodes every $10 \mathrm{in}$ along the array and thermocouples distributed between every other electrode. A total of 10 electrodes and 5 thermocouples make up the array

\subsection{Phase 1 Test Parameters and Test Ranges}

The sensor systems, test parameters and measurement ranges are provided in Table 1. 
Table 1. Sensor systems, parameters and ranges

\begin{tabular}{|l|l|l|l|}
\hline Sensor System & Test Parameter & Range & Comments \\
\hline Electrical Resistivity & $\begin{array}{l}\text { Reciprocal of } \\
\text { resistance }\end{array}$ & $\begin{array}{l}90 \text { percent of the data } \\
\text { within }+/-10 \text { percent }\end{array}$ & $\begin{array}{l}\text { Voltage may be increased } \\
\text { to maintain measurable } \\
\text { resistance }\end{array}$ \\
\hline Thermocouples & Temperature & 0 to 100 Celsius & $\begin{array}{l}\text { Fluid may lower or } \\
\text { increase temperature }\end{array}$ \\
\hline Advanced Tensiometers & Water level & $+/-200 \mathrm{~cm}$ & $\begin{array}{l}\text { Factory Calibration } \\
\text { (Attachment I) }\end{array}$ \\
\hline
\end{tabular}

\section{Sensor System Configuration}

To demonstrate the capability of the system in the MSTB, electrodes and thermocouple strings were constructed (Figure 1), placed in water and activated to collect measurements and demonstrate system functionality. Metal objects were placed in the test tank to demonstrate the effect of conducting objects on the measurements. A second test was performed by placing eight electrodes and thermocouples on two strings in a 4-foot tall column, filling the column with grout (Figure 2), and acquiring measurements as the grout cures. The complete system is illustrated on Figures 3 and 4. Advanced

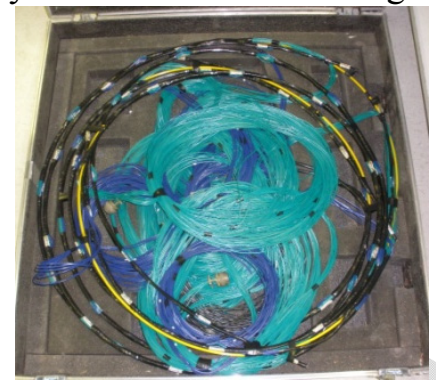

Figure 3. Arrays in shipping configuration tensiometers were calibrated at the factory and they were not configured for functionality testing at INL.

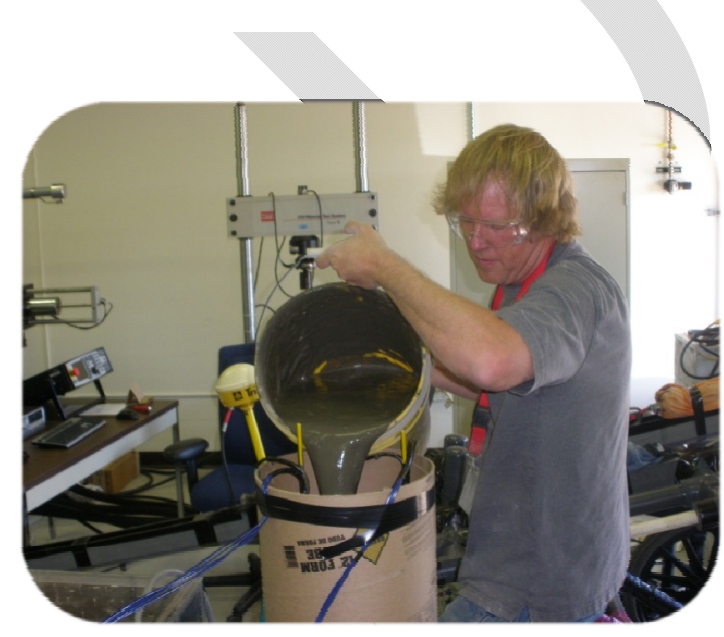

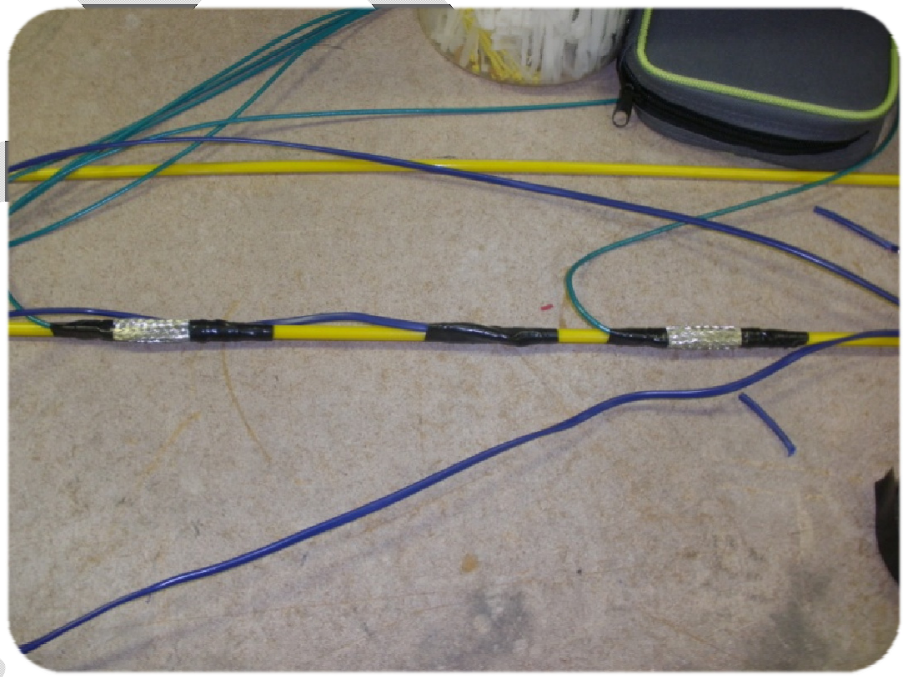

Figure 4. Construction of an electrode-thermocouple string. Picture shows only two electrodes (tin-plated copper) on either side of a thermocouple (i. e., a fraction of the entire string).

Figure 1. Filling the 4-foot column with grout. 


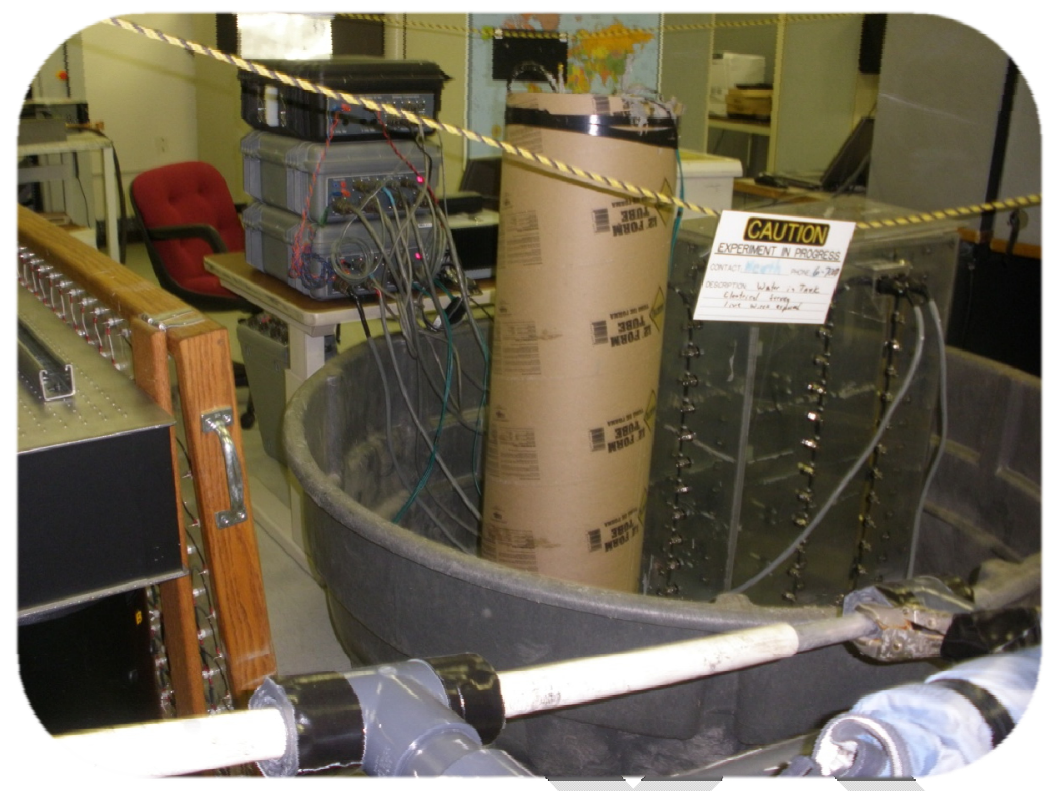

Figure 5. Concrete tube adjacent to water tank. Sensors hooked to multiplexers (gray boxes) and transmitter/receiver (black box).

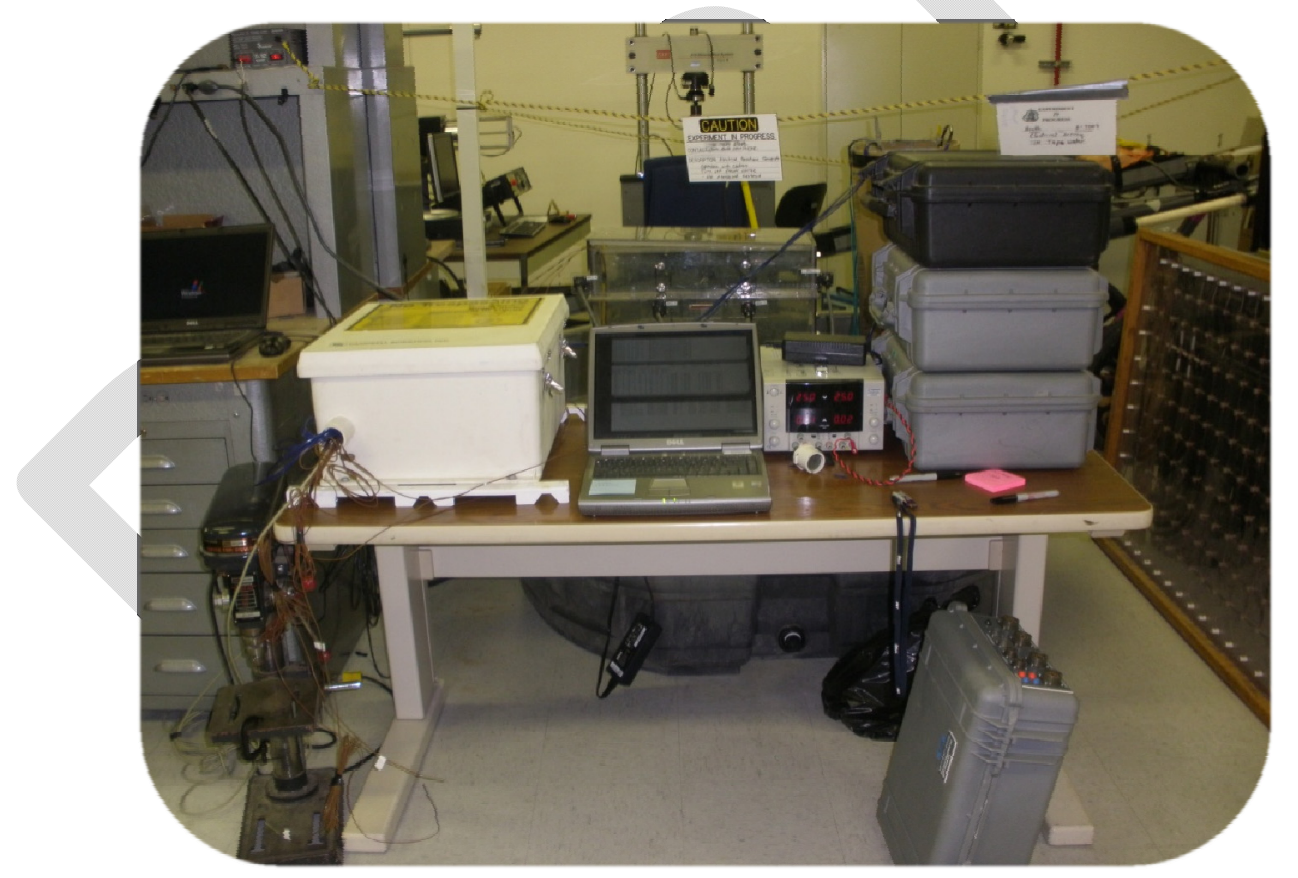

Figure 6. Front view of test setup. The white box is the Campbell enclosure for ADAMS controller for the thermocouples, with the control computer to left. Computer in middle of photo is for electrical resistivity system which is the two grey boxes 1 black box, power supply and laptop.

\subsection{System Calibration Testing}

Electrodes are not calibrated to an absolute resistivity value, as it is a difference in resistivity between changing environments that produces meaningful data. Calibration in resistivity cannot be 
thought of in the same way that a resister is calibrated that is an important part of the system, the earth, cannot be measured directly as a resister is so only parts of the system can be measured directly and calibrated the whole system can only be looked at by comparing the same data points collected slightly different times and compared and one could look at trends over time to see how the system is behaving. The ISDSN system will be calibrated by 1 ; the system contains a very precise voltage source that the system with measure every 10,000 measurements to insure that the internal electronics are functioning properly, 2; that during the data collection $100 \%$ reciprocity of data will be collected. Data reciprocity is where the receivers and transmitters are switched, see table 2, (An initial measurement is taken with one pair in transmission mode and the other in receiving mode, and a second measurement is obtained by switching the transmission-receiving mode on the electrode pairs. If the two sets of measurements agree within 10 percent, the electrodes are functioning properly) and the data collected again so the results from the two data points should be the same, the two are compared and if the difference between the points is less $+/-10$ percent $\left(10^{1}\right.$ to $\left.10^{-1}\right)$, with more than 90 percent of the data points falling within this range then the data sets are stable and the files can be processed with commercial inversion software. . Table 2 shows a partial set of measurements from the water tank data sets. Note that the transmitter and receiver values for Line 1 are the receiver and transmitter values for Line 990 and these measurements are within 10 percent of each other. In a similar fashion, Lines 2 and 991, Lines 3 and 992, etc, are compared and the measurements are within 10 percent.

Table 2. Measurement schedule and reciprocity results (V/I) for water tank electrodes.

\begin{tabular}{|c|c|c|c|c|c|c|c|c|c|}
\hline \multirow[t]{2}{*}{ Line \# } & \multicolumn{2}{|c|}{ Transmitter 1} & \multicolumn{2}{|c|}{ Transmitter 2} & \multicolumn{2}{|c|}{ Receiver 1} & \multicolumn{2}{|c|}{ Receiver 2} & \multirow{2}{*}{$\begin{array}{c}\text { Volts/Amps } \\
\qquad \backslash \mathrm{I}\end{array}$} \\
\hline & W & $E$ & W & $\mathrm{E}$ & W & E & W & $\mathrm{E}$ & \\
\hline 1 & 1 & 1 & 1 & 8 & 1 & 2 & 1 & 9 & $1.37 \mathrm{E}+02$ \\
\hline 990 & 1 & 2 & 1 & 9 & 1 & 1 & 1 & 8 & $1.37 \mathrm{E}+02$ \\
\hline 2 & 1 & 1 & 1 & 8 & 1 & 4 & 1 & 11 & $4.79 \mathrm{E}+01$ \\
\hline 991 & 1 & 4 & 1 & 11 & 1 & 1 & 1 & 8 & $4.79 \mathrm{E}+01$ \\
\hline 3 & 1 & 1 & 1 & 8 & 1 & 6 & 1 & 13 & $6.62 E+00$ \\
\hline 992 & 1 & 6 & 1 & 13 & 1 & 1 & 1 & 8 & $6.63 \mathrm{E}+00$ \\
\hline 4 & 1 & 1 & 1 & 8 & 1 & 10 & 2 & 2 & $-6.49 E+01$ \\
\hline 993 & 1 & 10 & 2 & 2 & 1 & 1 & 1 & 8 & $-6.49 \mathrm{E}+01$ \\
\hline 5 & 1 & 1 & 1 & 8 & 1 & 12 & 2 & 4 & $-3.77 \mathrm{E}+01$ \\
\hline 994 & 1 & 12 & 2 & 4 & 1 & 1 & 1 & 8 & $-3.77 \mathrm{E}+01$ \\
\hline 6 & 1 & 1 & 1 & 8 & 1 & 14 & 2 & 6 & $-1.76 \mathrm{E}+01$ \\
\hline 995 & 1 & 14 & 2 & 6 & 1 & 1 & 1 & 8 & $-1.76 \mathrm{E}+01$ \\
\hline 7 & 1 & 1 & 1 & 8 & 2 & 1 & 2 & 8 & $5.09 E+01$ \\
\hline 996 & 2 & 1 & 2 & 8 & 1 & 1 & 1 & 8 & $5.09 \mathrm{E}+01$ \\
\hline 8 & 1 & 1 & 1 & 8 & 2 & 3 & 2 & 10 & $4.21 \mathrm{E}+01$ \\
\hline 997 & 2 & 3 & 2 & 10 & 1 & 1 & 1 & 8 & $4.20 E+01$ \\
\hline 9 & 1 & 1 & 1 & 8 & 2 & 5 & 2 & 12 & $2.43 E+01$ \\
\hline 998 & 2 & 5 & 2 & 12 & 1 & 1 & 1 & 8 & $2.43 \mathrm{E}+01$ \\
\hline 11 & 1 & 1 & 1 & 8 & 2 & 9 & 3 & 1 & $-3.28 \mathrm{E}+01$ \\
\hline 1000 & 2 & 9 & 3 & 1 & 1 & 1 & 1 & 8 & $-3.27 E+01$ \\
\hline 12 & 1 & 1 & 1 & 8 & 2 & 11 & 3 & 3 & $-2.97 \mathrm{E}+01$ \\
\hline 1001 & 2 & 11 & 3 & 3 & 1 & 1 & 1 & 8 & $-2.97 \mathrm{E}+01$ \\
\hline 13 & 1 & 1 & 1 & 8 & 2 & 13 & 3 & 5 & $-2.27 \mathrm{E}+01$ \\
\hline 1002 & 2 & 13 & 3 & 5 & 1 & 1 & 1 & 8 & $-2.27 \mathrm{E}+01$ \\
\hline 14 & 1 & 1 & 1 & 8 & 2 & 15 & 3 & 7 & $-1.56 \mathrm{E}+01$ \\
\hline 1003 & 2 & 15 & 3 & 7 & 1 & 1 & 1 & 8 & $-1.56 \mathrm{E}+01$ \\
\hline 15 & 1 & 1 & 1 & 8 & 3 & 2 & 3 & 9 & $2.08 \mathrm{E}+01$ \\
\hline 1004 & 3 & 2 & 3 & 9 & 1 & 1 & 1 & 8 & $2.08 \mathrm{E}+01$ \\
\hline
\end{tabular}


Thermocouple calibration was performed by recording measurements in air and then immersing the thermocouples in a water-ice bath (approximately 0 degrees Celsius) to verify the measurement was in the range of $+/-2$ degrees $C$. The first thermocouple was touching the side of the container and records slightly higher values, relative to other thermocouples. Results are shown in Table 3.

Table 3. Thermocouple measurements before and immersed in ice bath.

\begin{tabular}{|c|c|c|c|c|c|}
\hline Date & Time & 1 & 2 & 3 & 4 \\
\hline $8 / 25 / 2011$ & $13: 00: 28$, & 21.960, & 21.910, & 22.610, & 22.790, \\
\hline $8 / 25 / 2011$ & $13: 00: 29$, & 21.960, & 21.910, & 22.610, & 22.790, \\
\hline $8 / 25 / 2011$ & $13: 00: 30$, & 1.400, & 0.490, & 0.460, & 0.520 \\
\hline $8 / 25 / 2011$ & $13: 00: 31$, & 1.400, & 0.490, & 0.460, & 0.520 \\
\hline $8 / 25 / 2011$ & $13: 00: 32$, & 1.400, & 0.490, & 0.460, & 0.520 \\
\hline & & & & & \\
\hline $8 / 25 / 2011$ & $13: 04: 40$, & 1.400, & 0.490, & 0.460, & 0.520 \\
\hline $8 / 25 / 2011$ & $13: 04: 41$, & 1.400, & 0.490, & 0.460, & 0.520, \\
\hline $8 / 25 / 2011$ & $13: 04: 42$, & 1.400, & 0.490, & 0.460, & 0.520, \\
\hline $8 / 25 / 2011$ & $13: 04: 43$, & 1.400, & 0.490, & 0.460, & 0.520, \\
\hline $8 / 25 / 2011$ & $13: 04: 44$, & 1.400, & 0.490, & 0.460, & 0.520 \\
\hline & & & & & \\
\hline $8 / 25 / 2011$ & $13: 10: 20$, & 1.340, & 0.460, & 0.400, & 0.520 \\
\hline $8 / 25 / 2011$ & $13: 10: 21$, & 1.340, & 0.460, & 0.400, & 0.520 \\
\hline $8 / 25 / 2011$ & $13: 10: 22$, & 1.340, & 0.460, & 0.400, & 0.520 \\
\hline $8 / 25 / 2011$ & $13: 10: 23$, & 1.340, & 0.460, & 0.400, & 0.520 \\
\hline $8 / 25 / 2011$ & $13: 10: 24$, & 1.340, & 0.460, & 0.400, & 0.520 \\
\hline & & & & & \\
\hline
\end{tabular}

Advanced tensiometers were calibrated at the factory and the certification sheet is provided in Attachment I.

\section{Functional/Operability Test Procedure}

The electrodes and thermocouples were configured as noted and illustrated above, and they were placed in a water tank and cement column to demonstrate the ability of the system to detect a change in resistivity and temperature. Electrode cables were hooked to a transmitter/receiver outside the tank and column, which in turn was connected to the control computer (Figures 3 and 4). Cables from the thermocouples were attached to multiple ADAMS 4018 controllers (white box in Figure 4), which in turn were connected to a second control computer. All wiring configurations and connections were properly isolated to prevent electrical hazards. An electrical field was induced by the computer by sending an $8 \mathrm{~Hz}, 50 \%$ duty cycle square wave to the transmitter. Hundreds of resistivity and temperature measurements were received and stored on the independent control computers for data processing using proprietary software. Metal objects were placed in proximity to the electrodes in the water tank and hundreds of measurements were recorded to demonstrate the influence of metal on the resistivity measurements. Example data files are provided in Attachments II (temperature) and III (resistivity).

Advanced tensiometers were calibrated at the factory and the certification sheet is provided in Attachment I. 


\section{Acquired Test Data Sets}

For the electrical resistivity system, a 'to do' file directs the execution of sampling schedules, with each schedule being a unique measurement sequence. Each sampling schedule results in a data file that is generated about every three to four minutes. The thermocouples are interrogated for a measurement every 5 minutes. Examples of the data files are given in Attachments II (thermocouples) and III (electrodes).

The sample frequency for electrodes during the functionality test is much greater than the planned sampling frequency for the FIU MSTB, as the electrodes placed in the FIU MSTB cannot be continuously sampled because they may interfere with other sensor measurements.

\section{Processed Data Results}

The ADAMS 4018 controllers convert the voltage from the thermocouples into degrees Celsius, and the only processing required is to reduce the number of readings from every second to every hour. Attachment II shows the direct read out from the ADAMS 4018 controllers and Table 4 shows the processed data for the cement column.

Table 4. Hourly temperature readings for the cement column.

\begin{tabular}{|c|c|c|c|c|c|}
\hline Date & Time & 0 & 1 & 2 & 3 \\
\hline $8 / 24 / 2011$ & 16:45:03, & 30.750, & 5.780 & 25.950, & 26.480, \\
\hline $24 / 2011$ & 17:45:29, & 30.950, & 920 & 2.900, & 1.290, \\
\hline $24 / 2011$ & 18:45:46, & 31.060, & 6.410, & 4.510, & 31.490, \\
\hline $8 / 24 / 2011$ & 19:45:40, & 31.750, & 37.240, & 35.690, & 31.670, \\
\hline $8 / 24 / 2011$ & $20: 45: 31$ & 33.390, & 39.600, & 37.610, & .190 \\
\hline $8 / 24$ & 21.45. & & 45 & & \\
\hline 11 & $22: 45$ & 42.870, & 0, & 90 & 40. \\
\hline 11 & 23:45:49, & 54.200, & 77.160, & 69.460, & 50.860, \\
\hline $8 / 25 / 2011$ & $00: 45: 40$ & 67.540, & 85.970, & 80.310, & 65.490, \\
\hline 11 & $01: 45:$ & 73.450, & 88.690, & 20, & 73.850 \\
\hline $8 / 25$ & :4 & 75.760, & 7.770, & & \\
\hline $8 / 25 / 20$ & 03:45: & 76.950, & 85.160, & 86.360, & 83.190, \\
\hline $8 / 25 / 2011$ & 04:45:07, & 76.900, & 81.680, & 3.740 & 83.320, \\
\hline $8 / 25 / 2011$ & 05:45:14, & 75.650, & 77.930, & 0.390, & 81.650, \\
\hline $8 / 25 / 2011$ & 06:45:47, & 73.900, & 74.140, & & 79.34 \\
\hline & 0 & , & .500 & & 0.000, \\
\hline $8 / 2$ & $08: 45: 27$ & 69.730, & .030, & 70.660, & 73.950, \\
\hline & $09: 3$ & 68. & 64.270, & 68. & 71.5 \\
\hline & 10 & 0, & 0.620 & & 68.1 \\
\hline $8 / 25$ & $11: 4$ & 63.050, & 58.070, & & 65. \\
\hline & & 61.030, & 20, & & 3.3 \\
\hline $8 / 25 / 2$ & $13: 45$ & 58.810, & 3.310 & 57 & $60 . \varepsilon$ \\
\hline $8 / 25 / 2011$ & 14:45:20, & 56.460, & 50.720, & 54.920, & 58.090, \\
\hline
\end{tabular}


A proprietary software algorithm is used to process the electrode data sets in Attachment III, and this step removes outlier values and provides QA/QC charts to assess the data set before final data reduction and image generation. Figure 5 plots the percent difference of the reciprocal resistivity versus the number of data sets, and the trending saw tooth pattern is a result of thermal effects in the grout as it cures. Calibration in resistivity is done in a few ways 1 ; the system contains a very precise voltage source that the system with measure every 10,000 measurements to insure that the internal electronics are functioning properly, 2 ; that during the data collection $100 \%$ reciprocity of data will be collected. Data reciprocity is where the receivers and transmitters are switched, see table 2, and the data collected again so the results from the two data points should be the same, the two are compared and if the difference between the points is less $+/-10$ percent $\left(10^{1}\right.$ to $\left.10^{-1}\right)$, with more than 90 percent of the data points falling within this range then the data sets are stable and the files can be processed with commercial inversion software (AGI's Earth Imager and CTECH's Environmental Visualization System) to generate the final resistivity image. Images for the concrete cylinder (Figure 6) and water tank, with and without metal objects (Figures 7 and 8), show the final processed product.

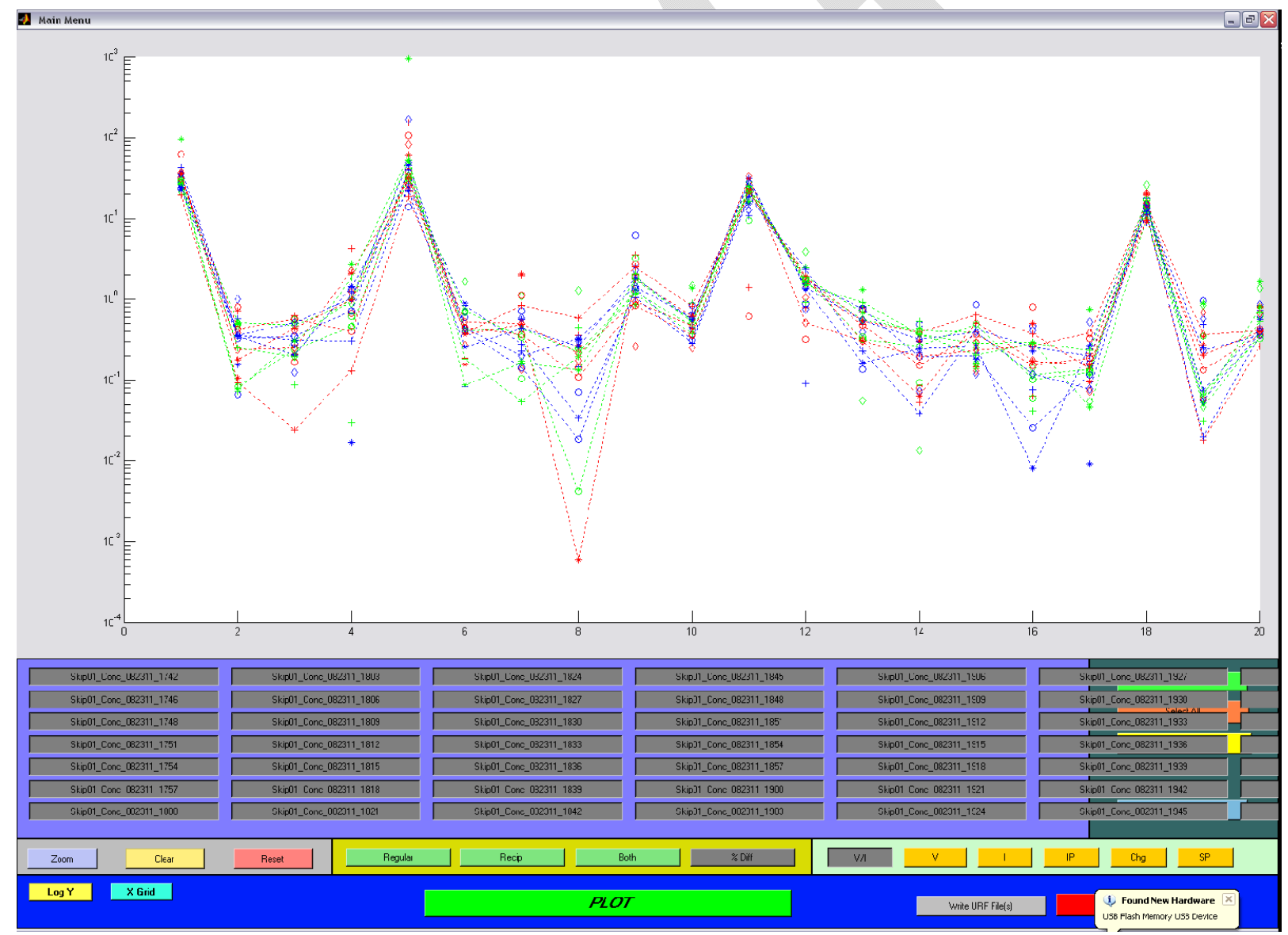

Figure 7. QA/QC plot showing percent difference in the reciprocal of the resistivity measurement (y axis) for electrode data sets obtained from the grouted column ( $\mathrm{x}$-axis is the number of data sets collected). 


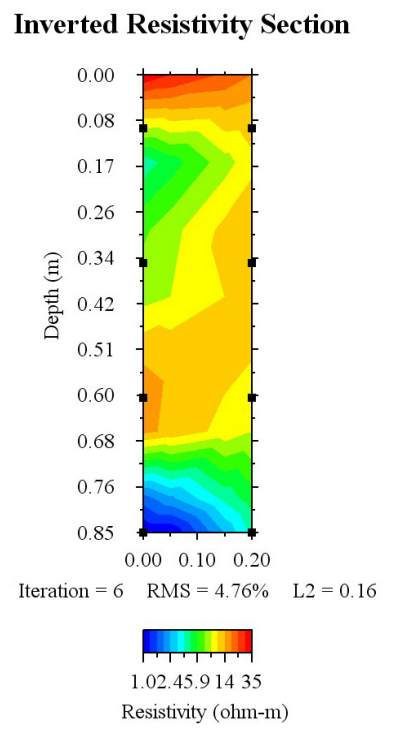

Figure 8. Resistivity image of grouted cylinder.

\section{Inverted Resistivity Image}
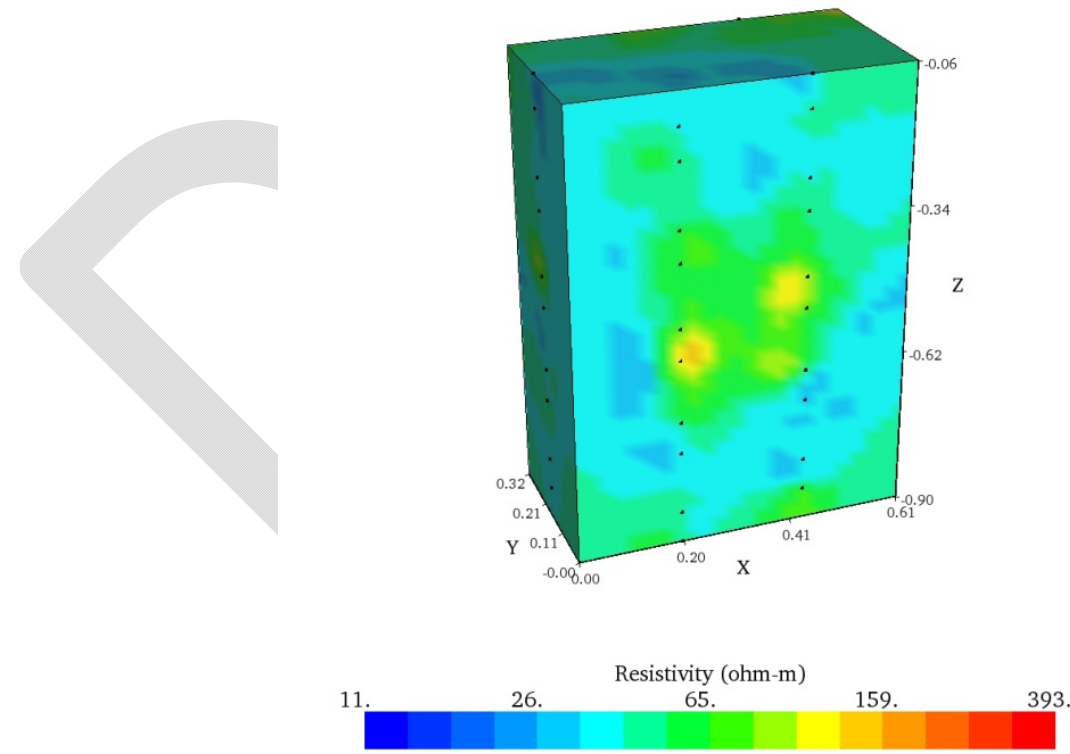

Figure 9. Image of water tank with water only. 


\section{Inverted Resistivity Image}
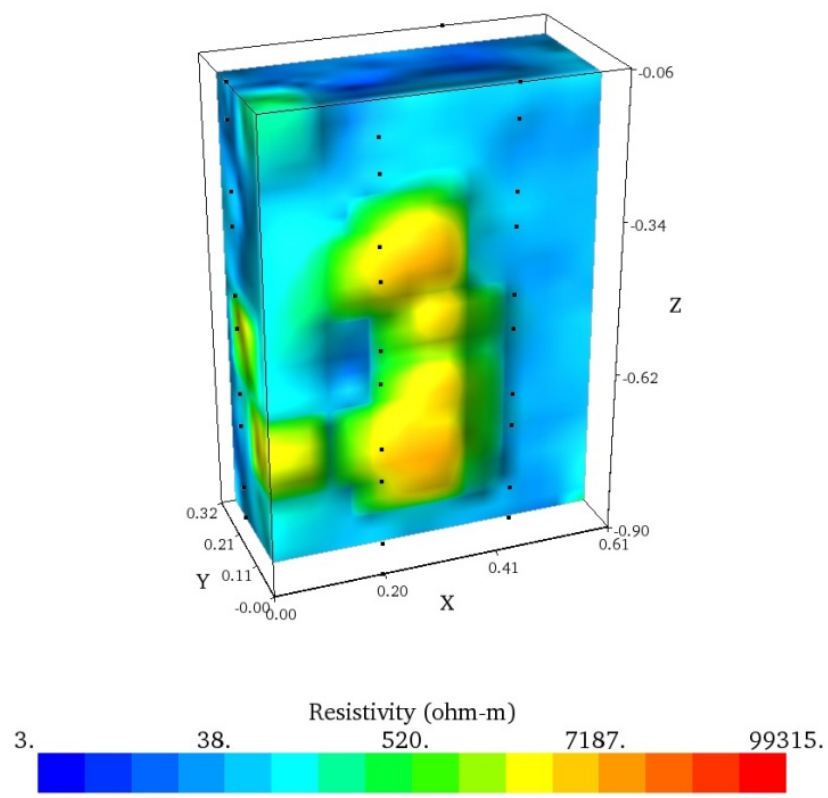

Figure 10. Image of water tank with metal object in water.

\section{Conclusions}

All Phase 1 test goals and objectives were met. The electrodes and thermocouples were calibrated and then deployed in water and grout media. All electric cables were insulated and the test area was roped off to identify the area as a potential hazard. Data files were generated and stored on the control computers. The electrode data files were processed to perform a QA/QC check prior to generation of the resistivity images. During Phase 2 testing in the FIU MSTB, the measurements obtained for the electrical resistivity system will have to be sequenced with other sensor systems to ensure that the measurement interrogation routine for the electrodes is carried out when other sensor systems are inactive. 


\section{Attachment I. Calibration Sheet for Advanced Tensiometers}

\section{CALIBRATION CERTIFICATION}

\section{Advanced Tensiometer Pressure Sensors}

This document certifies Advanced Tensiometer Pressure Sensors manufactured by Electronic Engineering Innovations are in compliance with engineering design, acceptance testing, and calibration control specifications.

\section{Sensor Calibration Procedure:}

Purchase No. Con $H E A T H$

1. Set Excitation Voltage To $+5 \mathrm{vdc}$

2. Set Calibration Temp. $22^{\circ} \mathrm{C}-$ Mercury Manometer $+/-200 \mathrm{~cm}$.

3. Connect DVM to Pressure Sensor and Temperature Output.

4. Zero Pressure Input - Set Off-Set Bias to +2.0vdc.

5. Apply $+200 \mathrm{~cm}$ Positive Input Pressure - Adjust for $4.0 \mathrm{vdc}$ Readout.

6. Apply $-200 \mathrm{~cm}$ Vacuum Input Confirm Readout Ovdc.

7. Record Readings for Five Point Calibration Curve-See Table Below.

8. Temperature Sensor Calibration - Submerse Sensor in Water Bath.

9. Water Bath $18^{\circ} \mathrm{C}$ for $10 \mathrm{Min}$ - Record Readout (Typ. Value .18vdc)

10. Temp Linear $+10.0 \mathrm{mV} /{ }^{\circ} \mathrm{C}$ Scale Factor $-0.5^{\circ} \mathrm{C}$ Accuracy

Guaranteeable at $+25^{\circ} \mathrm{C}$. Rated for Full $-55^{\circ}$ to $+150^{\circ} \mathrm{C}$ Range.

\begin{tabular}{|l|l|l|l|l|l|l|l|}
\hline Serial No. & Length & $\mathbf{+ 2 0 0}$ & $\mathbf{+ 1 0 0}$ & $\mathbf{0}$ Pres & $\mathbf{- 1 0 0}$ & $\mathbf{- 2 0 0}$ & $\begin{array}{c}\text { Temp } \\
189 \mathrm{C}\end{array}$ \\
\hline $072211-01$ & $20^{\prime}$ & 4.00 & 3.00 & 2.00 & 1.00 & .05 & $.196 \mathrm{~V}$ \\
\hline 072211.02 & $20^{\prime}$ & 4.00 & 3.01 & 2.00 & 1.00 & .02 & $.176 \mathrm{~V}$ \\
\hline $072211-03$ & $20^{\prime}$ & 4.00 & 3.00 & 1.99 & .99 & .03 & $.179 \mathrm{~V}$ \\
\hline & & & & & & & \\
\hline & & & & & & & \\
\hline & & & & & & & \\
\hline & & & & & & & \\
\hline
\end{tabular}

Wiring Diagram: (1) Red + Excitation Voltage, (2) Black Ground Common (3) Yellow Pressure Signal (4) Green Temp Signal

Certified By Cormy 70

Date: Jaly 22,2011 


\section{Attachment II. Example Data Set for Thermocouple Measurements.}

Date/Time, well_3_8ft, well_3_6ft, well_3_4ft, well_3_2ft, well_3_0ft,

$\begin{array}{lllllll}\text { Aug } 22 \text { 23:55:17, } & 35.400, & 35.200, & 35.170, & 35.230, & 35.200 \\ \text { Aug } 2223: 55: 18, & 35.400, & 35.200, & 35.170, & 35.230, & 35.200 \\ \text { Aug } 2223: 55: 19, & 35.400, & 35.200, & 35.170, & 35.230, & 35.200 \\ \text { Aug } 2223: 55: 20, & 35.400, & 35.200, & 35.170, & 35.230, & 35.200 \\ \text { Aug } 2223: 55: 21, & 35.400, & 35.200, & 35.170, & 35.230, & 35.200 \\ \text { Aug } 2223: 55: 22, & 35.400, & 35.200, & 35.170, & 35.230, & 35.200 \\ \text { Aug } 2223: 55: 23, & 35.400, & 35.200, & 35.170, & 35.230, & 35.200 \\ \text { Aug } 2223: 55: 24, & 35.400, & 35.200, & 35.170, & 35.230, & 35.200 \\ \text { Aug } 2223: 55: 25, & 35.400, & 35.200, & 35.170, & 35.230, & 35.200 \\ \text { Aug } 2223: 55: 26, & 35.400, & 35.200, & 35.170, & 35.230, & 35.200 \\ \text { Aug } 2223: 55: 27, & 35.400, & 35.200, & 35.170, & 35.230, & 35.200 \\ \text { Aug } 2223: 55: 36, & 35.400, & 35.200, & 35.170, & 35.230, & 35.200 \\ \text { Aug } 2223: 55: 37, & 35.400, & 35.200, & 35.170, & 35.230, & 35.200\end{array}$




\begin{tabular}{|c|c|c|c|c|c|}
\hline Aug 22 23:55:38, & 35.400 & 35.200 & 35.170 & 35.230 & 35.200 \\
\hline Aug 22 23:55:39, & 35.400 & 35.200 , & 35.170 & 35.230, & 35.200 \\
\hline Aug 22 23:55:40, & 35.400 & 35.200 & 35.170 & 35.230 & 35.200 \\
\hline Aug 22 23:55:41, & 35.400 & 35.200 & 35.170 & 35.230, & 35.200 \\
\hline Aug 22 23:55:42, & 35.400 & 35.200 & 35.170 & 35.230 & 35.200 \\
\hline Aug 22 23:55:43, & 35.400 & 35.200 & 35.170 & 35.230, & 35.200 \\
\hline Aug 22 23:55:44, & 35.400 & 35.200 & 35.170 & 35.230 & 35.200 \\
\hline Aug 22 23:55:45, & 35.400 & 35.200 & 35.170 & 35.230 & 35.200 \\
\hline Aug 22 23:55:46, & 35.400 & 35.200 & 35.170 & 35.230 & 35.200 \\
\hline Aug 22 23:55:47, & 35.400 & 35.200 & 35.170 & 35.230 & 35.200 \\
\hline Aug 22 23:55:48, & 35.400 & 35.200 & 35.170, & 35.230, & 35.200 \\
\hline Aug 22 23:55:49, & 35.400 & 35.200, & 35.170 & 35.230 & 35.200 \\
\hline Aug 22 23:55:50, & 35.400 & 35.200 , & 35.170 & 35.230 & 35.200 \\
\hline Aug 22 23:55:51, & 35.400 & 35.200 & 35.170 & 35.230 & 35.200 \\
\hline Aug 22 23:55:52, & 35.400 & 35.200 & 35.170, & 35.230 & 35.200 \\
\hline Aug 22 23:55:53, & 35.400 & 35.200 , & 35.170 & 35.230 & 35.200 \\
\hline Aug 22 23:55:54, & 35.400 & 35.200 & 35.170 & 35.230 & 35.200 \\
\hline Aug 22 23:55:55, & 35.400 & 35.200 & 35.170 & 35.230 & 35.200 \\
\hline Aug 22 23:55:56, & 35.400 & 35.200 & 35.170 , & 35.230, & 35.200 \\
\hline Aug 22 23:55:57, & 35.400 & 35.200 & 35.170 & 35.230 & 35.200 \\
\hline Aug 22 23:55:58, & 35.400 & 35.200 & 35.170 & 35.230 & 35.200 \\
\hline Aug 22 23:55:59, & 35.400 & 35.200 & 35.170 & 35.230 & 35.200 \\
\hline Aug 22 23:56:00, & 35.400 & 35.200 & 35.170 & 35.230 & 35.200 \\
\hline Aug 22 23:56:01, & 35.400 & 35.200 & 35.170 & 35.230 & 35.200 \\
\hline
\end{tabular}




\section{Attachment III. Example Data File for Electrical Resistivity System}

Batch File Run Started with MPTERTBackground. Standard Data Run Without Restart

Date: $8 / 24 / 2011$

Time: 8:07:59 AM

Number of Cycles: $3 \quad$ New Gains used?: True

Delay Time (ms): $20 \quad$ Update gains?: True

Measuring Time (ms): $16.66667 \quad$ Calibrate Update Interval: 1000

Post Measuring Time (ms): 3 \# of windows: 1

Resistance Constant: $1 \quad$ Measure Self Potential: True

Average Current Tolerance: 0.00001

Topology File Name: C:\MPTERTField\Topology\Tank_Mux004_Mux017.TOP

Measurement Schedule File Name: C:\MPTERTField $\backslash$ Schedule $\backslash$ Skip07_Inc02_Tank.sch

Batch File Name: C:\MPTERTField\Batch $\backslash$ Skip07_Inc02_Tank

TX RX Resistance Chargebility IP WINDOW 1 Current Self Potential

WE $\mid$ W E | W E | W E $\quad$ V $\backslash$ I $\quad$ Std Window $1 \mathrm{MV} / \mathrm{V}$ Value $\quad$ Std $\quad$ (AMPS) (Volts) 1978

$\begin{array}{ccccccccccccccccccc}1 & 1 & 1 & 1 & 8 & 1 & 2 & 1 & 9 & 1.37102 \mathrm{e}+02 & 2.5 \mathrm{e}-02 & .28 & 3.86690 \mathrm{e}-02 & 3.0 \mathrm{e}-03 & 4.82297 \mathrm{e}-02 & 1.69875 \mathrm{e}-01 & 2 & 4 \\ 2 & 1 & 1 & 1 & 8 & 1 & 4 & 1 & 11 & 4.79277 \mathrm{e}+01 & 9.7 \mathrm{e}-03 & .04 & 1.75582 \mathrm{e}-03 & 2.5 \mathrm{e}-05 & 4.83410 \mathrm{e}-02 & 4.70382 \mathrm{e}-02 & 2 & 3 \\ 3 & 1 & 1 & 1 & 8 & 1 & 6 & 1 & 13 & 6.62144 \mathrm{e}+00 & 1.2 \mathrm{e}-03 & 6.07 & 4.02251 \mathrm{e}-02 & 2.0 \mathrm{e}-04 & 4.83367 \mathrm{e}-02 & 2.13682 \mathrm{e}-01 & 2 & 3 \\ 4 & 1 & 1 & 1 & 8 & 1 & 10 & 2 & 2 & -6.49167 \mathrm{e}+01 & 9.2 \mathrm{e}-03 & .20 & -1.30141 \mathrm{e}-02 & 3.5 \mathrm{e}-04 & 4.82525 \mathrm{e}-02 & 1.04417 \mathrm{e}-01 & & 2 & 4 \\ 5 & 1 & 1 & 1 & 8 & 1 & 12 & 2 & 4 & -3.77275 \mathrm{e}+01 & 2.0 \mathrm{e}-03 & .33 & -1.26203 \mathrm{e}-02 & 1.4 \mathrm{e}-04 & 4.81210 \mathrm{e}-02 & 1.89162 \mathrm{e}-01 & 2 & 3 \\ 6 & 1 & 1 & 1 & 8 & 1 & 14 & 2 & 6 & -1.76043 \mathrm{e}+01 & 6.9 \mathrm{e}-04 & .07 & -1.23841 \mathrm{e}-03 & 1.4 \mathrm{e}-04 & 4.80142 \mathrm{e}-02 & 4.06099 \mathrm{e}-01 & 2 & 3 \\ 7 & 1 & 1 & 1 & 8 & 2 & 1 & 2 & 8 & 5.09372 \mathrm{e}+01 & 8.3 \mathrm{e}-03 & .41 & 2.08165 \mathrm{e}-02 & 7.3 \mathrm{e}-04 & 4.78298 \mathrm{e}-02 & -9.97667 \mathrm{e}-02 & 2 & 4 \\ 8 & 1 & 1 & 1 & 8 & 2 & 3 & 2 & 10 & 4.20571 \mathrm{e}+01 & 7.8 \mathrm{e}-03 & .39 & 1.65361 \mathrm{e}-02 & 8.6 \mathrm{e}-05 & 4.78367 \mathrm{e}-02 & -1.82110 \mathrm{e}-01 & 2 & 3 \\ 9 & 1 & 1 & 1 & 8 & 2 & 5 & 2 & 12 & 2.43474 \mathrm{e}+01 & 4.5 \mathrm{e}-03 & .41 & 1.00711 \mathrm{e}-02 & 7.3 \mathrm{e}-05 & 4.77913 \mathrm{e}-02 & 4.80096 \mathrm{e}-01 & 2 & 3\end{array}$


$\begin{array}{lllllllllllllllll}10 & 1 & 1 & 1 & 8 & 2 & 7 & 2 & 14 & 8.24126 \mathrm{e}+00 & 1.7 \mathrm{e}-03 & .35 & 2.84514 \mathrm{e}-03 & 1.2 \mathrm{e}-04 & 4.77573 \mathrm{e}-02 & 1.26080 \mathrm{e}-02 & 2\end{array}$

$\begin{array}{lllllllllllllllll}11 & 1 & 1 & 1 & 8 & 2 & 9 & 3 & 1 & -3.27972 \mathrm{e}+01 & 6.0 \mathrm{e}-03 & .10 & -3.37662 \mathrm{e}-03 & 1.8 \mathrm{e}-04 & 4.77549 \mathrm{e}-02 & 3.83790 \mathrm{e}-01 & 2\end{array}$

$\begin{array}{llllllllllllllllll}12 & 1 & 1 & 1 & 8 & 2 & 11 & 3 & 3 & -2.97379 \mathrm{e}+01 & 5.9 \mathrm{e}-03 & .25 & -7.55311 \mathrm{e}-03 & 2.7 \mathrm{e}-04 & 4.77477 \mathrm{e}-02 & 5.71668 \mathrm{e}-01 & 2\end{array}$

$\begin{array}{lllllllllllllllll}13 & 1 & 1 & 1 & 8 & 2 & 13 & 3 & 5 & -2.27064 \mathrm{e}+01 & 4.3 \mathrm{e}-03 & .27 & -6.15205 \mathrm{e}-03 & 1.1 \mathrm{e}-04 & 4.77277 \mathrm{e}-02 & 4.56370 \mathrm{e}-01 & 2\end{array}$

$\begin{array}{llllllllllllll}14 & 1 & 1 & 1 & 8 & 2 & 15 & 3 & 7 & -1.55916 \mathrm{e}+01 & 3.4 \mathrm{e}-03 & .51 & -7.90704\end{array}$ 